\title{
EFFECT OF BEDFORMS ON VELOCITY DISTRIBUTION IN ALLUVIAL CHANNEIS
}

\author{
M.I. Attia
}

Assoc. Prof. Water and Water Structure Eng. Department,

Faculty of Eng., Zagazig University

M.M Ezzeldin

Prof. Irrigation and Hydraulics Department

Faculty of Eng. Mansoura University.

$$
\text { تأثير القاع المنعرج علي منحني توزيع اللسرعات في القنوات المفتوحة }
$$

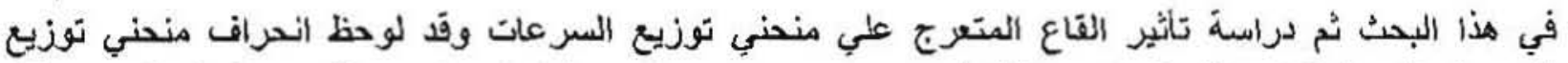

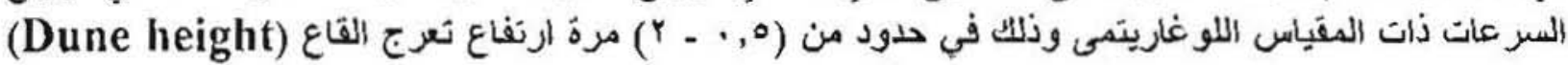

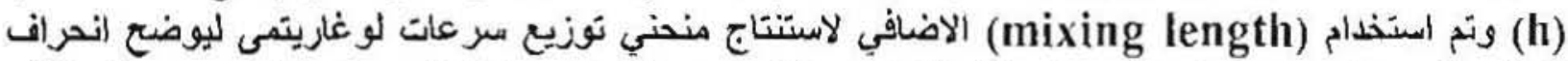

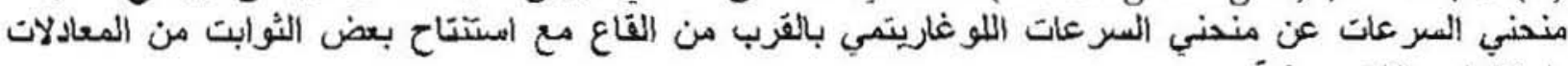

$$
\text { باستخدام بيانات هعلية. }
$$

\section{ABSTRACT}

Velocity distribution over pronounced rough surfaces shows a deviation from log- law for small values of $y$. In the case of duned bed, this distance may be 0.5 to 2 times the dune height. The concept of additional mixing length was used to obtain a $\log$ - law which shows deviation in velocity from log- law near the bed and constants appearing in the equation were evaluated using experimental data from flume studies.

\section{INTRODUCTION}

Basic work on velocity distribution in hydrodynamically smooth and rough pipes was carried out by Karman and prandtl who gave well known log- velocity distribution lows. Keulegan(1) used these velocity distribution laws and determined the constants in volocity distribution and resistance laws using Bazin's data.

When these velocity distribution laws were used for alluvial channels with pronounced bed roughness in the form of dunes, certain difficulties were encountered primarily due to separation of flows behind dunes, its reattachment, and redevelopment of the flow from the point of reattachment to the crest of the dune. Overlooking these complications, Einstein(2) suggested that if $u$. in the velocity distribution law was replaced by, $u_{*}$ the shear velocity corresponding to grain roughness, the velocity distribution law for plain bed can be used for duned bed. However, since then many investigators have attempted to verify Einstein's equation for velocity distribution over duned bed using laboratory and field deta and have found large deviations from the 
low. The deviations are primarily due to Karman constant, $k$ being different from 0.04 and due to variation in additive constant and length scale.

Earlier studies by several investigators had shown that for relatively large values of relative roughness, i.e height of roughness to depth ratio, there was a departure from log-velocity distribution relationship near the bed. It is expected that similar situation would occur in case of flow over duned bed. The problem is further complicated by the separation of flow behind the dune and the reattachment of flow from the point of reattachment up to the crest of the dune. In the latter portion, the velocity distribution will be gradually changed along upstream face of the dune.

Thus prediction of velocity distribution over duned bed is a very complex problem. A few attempts have been made to determine the velocity distribution law by making some simplifying assumptions. One of these attempts, using additional mixing length approach, was earlier used by Singhal (3), and Garde and Kaka (4) for rough beds with uniform roughness. Here, the deviation from log-taw was attributed to generation and diffusion of additional turbulence caused large roughness and was accounted by introductive an additional mixing length, $l_{\text {. }}$.

In the present research, this idea is extended to the case of flow over a duned bed, by first defining an average velocity distribution between point of reattachment and dune crest and then determining the parameters in the velocity distribution law from the analysis of experimental data.

\section{EARLER STUDIES:}

Few attempts have been made earlier to describe the velocity distribution over duned surface. Einstein (2) gave an equation for velocity distribution over smooth, in transition, and rough beds in the form

$$
\frac{f_{u}}{u .}=5.75 \log \left(30.2 \frac{y_{y}}{d_{s 5}}\right) \ldots . .
$$

In which:

$u=$ Velocity at a distance $y$ from bed $\mathrm{u},=$ Shear velocity corresponding to grain roughness

$d_{65}=$ Size of bed material such that 65 per cent of material finer than this size.

$x=$ Function of $d_{\omega} d \partial^{\prime}$

ó-Thickness of laminar sublayer.

Since shear velocity corresponding to grain roughness has been used instead of $u_{0}$, the equation is supposed to be applicable to duned bed also. However, verification using flume data have shown large variations between computed and observed velocity distributions.

Garde(5), and Garde and Paintal(6)have studied variation of $x$ and in E.q.2 using flume and field data.

$$
\frac{u}{u \cdot}=\frac{2.307}{k} \log \left(\frac{y}{k}\right) \ldots \ldots
$$


They related variation of $k+\frac{\tau_{0}}{\sigma r_{s} d}$

and variation of $\frac{k_{5}^{\prime}}{d}+\frac{\tau_{0}}{\Delta r_{5} d} d r_{5} d$ And $\frac{u}{\sqrt{\left(\Delta r_{s} / p r\right) d}}$

Here

$\tau_{0}=$ Average shear stress on the bed

$P_{r}=$ Mass density of the fluid

$\Delta \mathbf{r}_{3}=$ Difference in the specific weight coefficient. sediment and water d= Median size of the sediment

Earlier studies have indicated that Karman - Prandtl velocity distribution equations were not valid close to the boundary when surface roughness to depth ratio is relatively large. This is attributed to generation and diffusion of large scale turbulence near the bed. Therefore, Singhal(3)assumed that mixing length $I$ is given by.

$\mathbf{l}=\mathbf{k y}+\mathrm{I}_{0}$

Where $l_{0}$ is the additional mixing length.

Using this equation for the mixing length, the following equation for velocity distribution was obtained

$\frac{\mathrm{u}}{\mathrm{u} \cdot}=\frac{1}{\mathrm{k}} \ln \left(-\frac{\mathrm{Y}}{\mathrm{k}_{\mathrm{s}}}+\frac{\mathrm{l}_{0}}{\mathrm{k} \cdot \mathrm{k}_{\mathrm{s}}}\right)+\mathrm{B}_{1} \ldots$.

in which

$K_{s}=$ Height of the roughness element $\mathbf{B}_{1}=$ constant of integration

He collected experimental data on velocity distribution over closely packed uniform sand, particles on the bed of the flume. His analysis indicated that additional mixing length in dimensionless form $I_{0} / \mathbf{k} . K_{s}$ decreases with an increase in $D / K_{\text {s }}$ .He obtained $B_{1}$ as 7.50. Here $y$ is the depth of flow.

Garde and Kaka (4) conducted experiments on resistance to flow with artificial roughness which was formed by spheres arranged in different concentrations. They also confirmed the deviation from log law near the bed for the velocity profile. Integrating the velocity distribution law in the from of Eq. 4 they obtained the following equation for average velocity in the vertical direction as follows:

$$
\begin{gathered}
\frac{u}{u}=\sqrt{\frac{8}{f}}-\frac{2.3}{k}\left(1+\frac{l_{0}}{D k}\right) \log \\
\left(\frac{D}{k}+\frac{l_{0}}{k K_{s}}\right)+\left(B_{1}-\frac{l_{v}}{k}\right) \ldots \ldots
\end{gathered}
$$

where $\mathrm{f}$ is friction factor. Using the above equation, they found that $\left(\mathrm{I}_{0} / \mathrm{K}_{\mathrm{s}} . \mathrm{M}\right)$ decreases with increase in $\mathrm{D} / \mathrm{K}$,

where $\mathbf{M}$ is a function of concentration of roughness. Constant $B_{1}$ in the above equation was also found to vary with the concentration of the roughness spheres but did not seem to be a function of shape of the roughness element.

Mendoza and Shen (7) have used K$€$ turbulence model and compared the observed velocity distribution at different sections along dune length with the observed ones for one run. They found good conformity between them.

Paris (8) subdivided the entire flow region into two layers. The thickness $y_{\mathrm{s}}$ of lower region in dimensionless from $y_{3} / h$ seemed to be related $h / L$, where $h$ and $L$ are height and length of undulations. The velocity distribution in both layers was assumed to be logarithmic.

Xiaonan and Don Guoren (9) assumed a complex logarithmic distribution and determined the constants in the 
equation using the experimental data.

\section{DATA}

Extensive experiments were conducted in a $2.5 \mathrm{~m}$ wide flume bed materials with median sizes 0.19 , $0.27,0.32,0.450 .47$ and $0.93 \mathrm{~mm}$ were used. Of these experiments, data pertaining to dunes only were selected and used in the present research. Velocity observation were made along the depth at three locations across the width of the flume. All available velocity profiles in the region between section of reattachment and crest of the dune for selected runs were used. Other details such as depth, slope, height and length of dunes etc. were also noted.

\section{ANALYSIS OF DATA AND DISCUSSION}

The above mentioned velocity distribution data have been analyzed using Eq. 4 with characteristic length as the dune height $\mathrm{h}, \mathrm{i}, \mathrm{e}$.

$$
\frac{\mathrm{u}}{\mathrm{u} \cdot}=\frac{\mathrm{I}}{\mathrm{k}} \ln \left(\frac{\mathrm{y}}{\mathrm{h}}+\frac{\mathrm{I}_{\mathrm{b}}}{\mathrm{kh}}\right)+\mathrm{B} \text {, }
$$

Typical velocity distribution from selected runs are plotted on semi- log paper as $u / u$. versus $y / h$ as showa in Fig. 1.

It can be seen that velocity distribution deviates from the loglaw below certain values of $y / h$ which in case of Fig.1 varies from $y / h=0.5$ to about 2.0. Similar tendencies were observed in all other runs. For a given velocity profile, the value of Karman's constant was determined as follows:
$K=\frac{2.307}{\text { Slope of straight line over one cycle }}$

It may be mentioned that $k$ values are normally determined from the lowest $\mathbf{1 0}$ to 15 percent of the depth. However, since in the present study the deviation in the velocity distribution occurred in the lower positions was determined from the upper portion of the velocity distribution data.

Average values of $(\mathrm{l} / \mathrm{k} . \mathrm{h})$ were determined for a given run from the lowest 2 or 3 points which deviated from the straight line relationship. Lastly, for $y / h$ values much greater than $\left(l_{0} / k . h\right)$ the tatter was neglected and $B_{1}$ was then determined from known values of $\left(u / u r_{1}\right.$ and $k$.

Taking a clue from earlier studies of Singhal, and Garde and Kaka , it was assumed that $k, l_{0} / \mathrm{h}$, and $B_{1}$ would essentially depend upon the geometric characteristics of the bed undulations. Fig2 shows the variation of $k$ with $/ \mathrm{h}$. It was seen that for very large values of $1 / \mathrm{h}$ (i.e. when the bed becomes essentially plain) $k$ approaches 0.37 , a value close to the one obtained for flow in pipes and channels with sand grain roughness. It was increased to about 0.58 as $\mathrm{L} / \mathrm{h}$ tends to zero.

In order to systematize the scatter, $k$ was also plotted against $D / h$ as shown in Fig. 3, where similar tendency was noticed. Combining the results of Fig. 2 and 3 , the following equation was obtained for the variation of $\mathrm{k}$ with $\mathrm{D} / \mathrm{h}$ and $\mathrm{l} / \mathrm{h}$

$.\left(k-k_{s}\right)=0.19\left(\frac{D}{h}\right)^{-0.60}-0.001\left(\frac{L}{h}\right)(7)$ 
Where $k_{0}$ is the limiting value of $k$ which equals to 0.37 . With known values of $k, l_{0} / h$, which were computed for all velocity data, and the influence of variation in $D / h$ and $1 / h$ on $I_{0} / h$ was studied. It was found that effect of variation in $\mathrm{L} / \mathrm{h}$ on $\mathrm{l}_{0} / \mathrm{h}$ was relatively insignificant compared to the effect of $D / h$.Therefore, $\mathrm{L}_{0} / \mathrm{h}$ was related to $\mathrm{D} / \mathrm{h}$ only as shown in Fig.4.

It can be seen from Fig. 4 that $l_{0} / \mathrm{h}$ increases as $\mathrm{D} / \mathrm{h}$ increases from very small values up to $a \mathrm{D} / \mathrm{h}$ value of 16. Beyond that value, $l_{0} / \mathrm{h}$ seems to decrease with increase in $\mathrm{D} / \mathrm{h}$; however there were not enough data points to establish a mathematical relationship. Therefore, Eq. 8 gives a variation in $I_{0} / \mathrm{h}$ with $\mathrm{D} / \mathrm{h}$ such that $\mathrm{I}_{0} / \mathrm{h}$ reaches maximum value of 0.16 where $\mathrm{D} / \mathrm{h}$ equals 16 .

$\frac{l_{0}}{h}=0.16\left(1-\mathrm{e}^{-0.175(\mathrm{D} / \mathrm{h})}\right) \ldots \ldots$

With the avaiability of additional data for higher values of $\mathrm{D} / \mathrm{h}$, this equation may need modification.

Similer analysis was also carried to study the effect of vartiation in $D / h$ and $L / h$ on the additive constant $B_{1}$. Here, the effect of $D / h$ on $B_{1}$ was found to be much smaller than that of $\mathrm{L} / \mathrm{h}$.Fig 5 shows variation of $B_{1}$ with $L / h$ which can be expressed by the following equation:

$\mathrm{B}_{1}=8.5+5\left(1-\mathrm{e}^{-0.04(\mathrm{~L} / \mathrm{h})}\right) \ldots \ldots \ldots$

It my be noted that as $L / h$ approaches zero, the constant equals 8.5 as in the case of conventional semi-log velocity distribution law and with increase in $L / h$ the constant increases and attains a value of 13.5.
The above information can be utilized for predicting the velocity distribution over a duned bed if the depth of flow, slope, and height and length of the dunes are known. This method was applied to three runs of Barton and Lin (11) (sediment size $0.19 \mathrm{~mm}$ ) and two runs of Lauresen (12), (Sediment size $0.01 \mathrm{~mm}$ ) having dune bed configuration. It was noticed that the predicted velocity profiles overestimate the velocity at any elevation by about 10 percent. The scatter on Fig.5 indicates the possibility that may depend on some other flow parameters; one of the parameters can be $(\mathrm{u} . \mathrm{d} / \gamma)(13)$. This needs further study.

\section{CONCLUSION}

Effect of dunes on velocity distribution in alluvial channels was examined. Extending the concept of additional mixing length as proposed by Singhal, and Garde and Kaka to flow over duned beds, Eq.6 was used to analyze the velocity distribution data of Guy et al. the estimated parameters in the velocity distribution law were related to the roughness cbaracteristics i.e. to $\mathrm{L} / \mathrm{h}$ and, D/k, Karman constant $\mathrm{k}$ was found to be function of $L / h$, and $\mathrm{D} / \mathrm{h}$, while $\mathrm{I}_{0} / \mathrm{h}$ was function of only $D / h$ and $B 1$ only a function of $L / h$. A very limited verification of the equation indicated that the possibility that may be a function of some flow parameter such as $\left(u^{*} \cdot d / \gamma\right)$ 


\section{REFERENCES}

1. Keulegan G.H Laws of Turbulent Flow in Open Channels U.S Department of Commerce, NBS, Vol. 21, Dec. 1938.

2. Einstein, H.A. the Bed- Load Function for Sediment Transportation in Open Channel Flows. USDA, Tech. Bull, No. 1026, 1950.

3. Singhal, p.p Velocity Distribution over Extreme Rough Surfaces. M.E. Thesis, Civil Engg. Deptt. University of Roorkee (UP), 1969.

4. Garde, R.J. and kaka, N.M.Velocity Distribution and Resistance to Flow in Artificially Roughened Open Channels. $6^{\text {th }}$ Australasian Hydrauties and Fluid Mechanics Conference, Adelaide (Australia). Dec, 1979

5. Garde, R.J.Total Sediment Transport in Alluvial Channels. Ph.D Thesis, Colorado State University, Fort Collins (USA), 1959.

6. Garde, R.J. and Paintal, A.S. Velocity Distribution in Alluvial Channels. Le Houille Blanche, No. 4, 1964.

7. Mendoza, Cand Shen, H.W. Steady Two Dimensional Flow Over Dunes, Proc. Of $21^{\text {II }}$ IAHRCongress, Melbourne (Australia), vol. 2,1985.

8. Paris, E. Velocity distribution Over Macroscale Roughness, Preliminary Results, Fourth International) Symposium on River Sedimentations, Beijing (China), 1989.
9. Xiaonan, T. and Guoren,D. Experimental Study of Open Channel Flow Over Dunes. Internationl Symposium on Hydraulic Research in Nature and Laboratory. Vol. 2, Wuhan (China), 1992.

10. Guy. H.P, Simons, D.B, and Richardson, E.V. Summary of Alluvial Channels Data from Flume Expts. 1956-61, USGS paper No. 462-1. 1966.

11. Barton, J.R. and Lin P.N. A Study of Sediment Transport in Alluvial Channels. Colorado State University, Rep. No. 55,JRB2,1955 .

12. Laursen, E.M An Investigation of Total Sediment Load IAHR, State University of Lowa, June, 1957.

13. Garde, R.J. Tubulent Flow, Wiley Eastern Ltd., New Delhi, 1994. Chapter VIII. 
Manseura Engineering Journal, (MEJ), Vol. 31, No. 4, I (2ecember 2006.

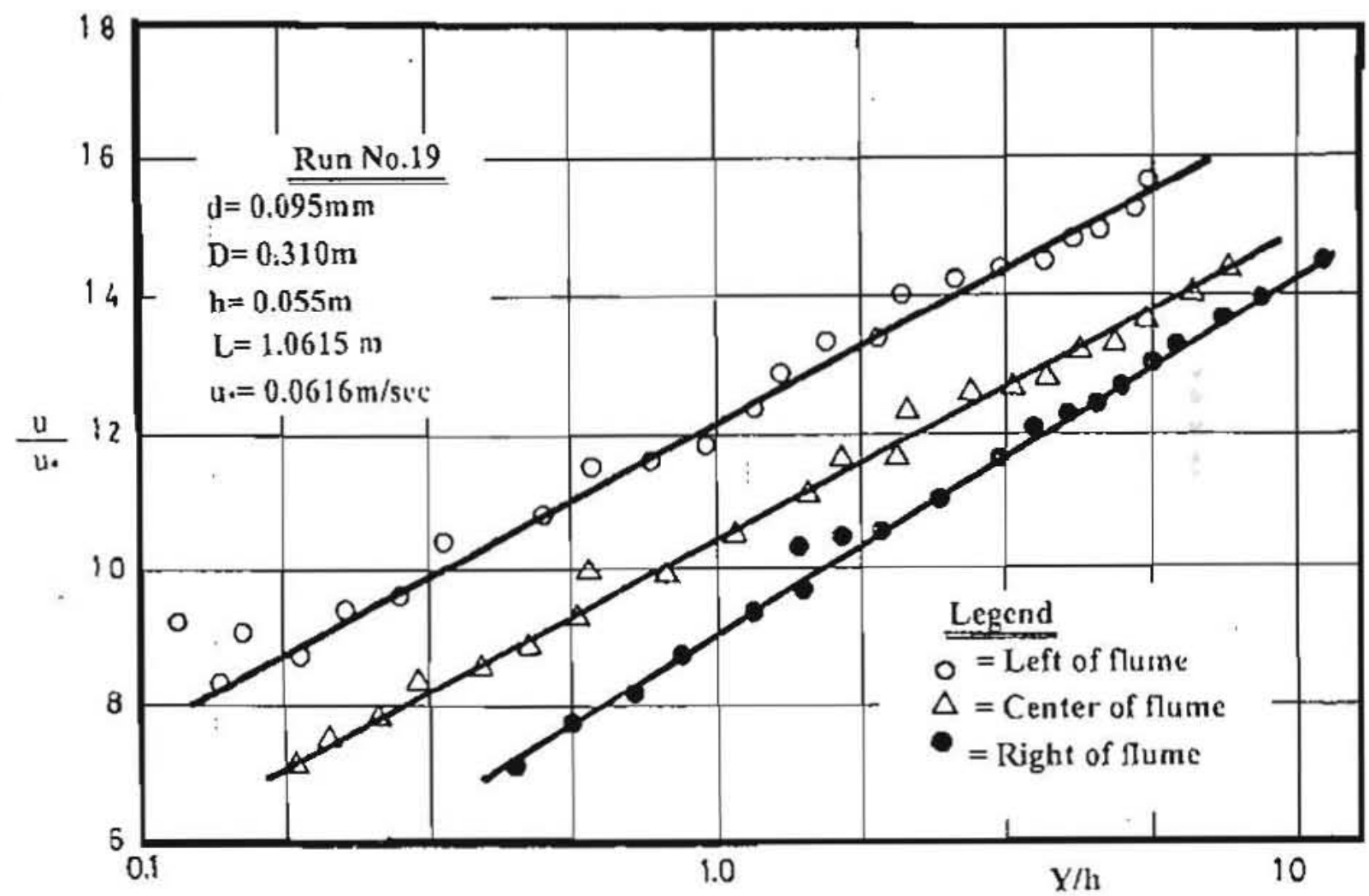

Fig. (1) Typical velocity distribution over duned bed.

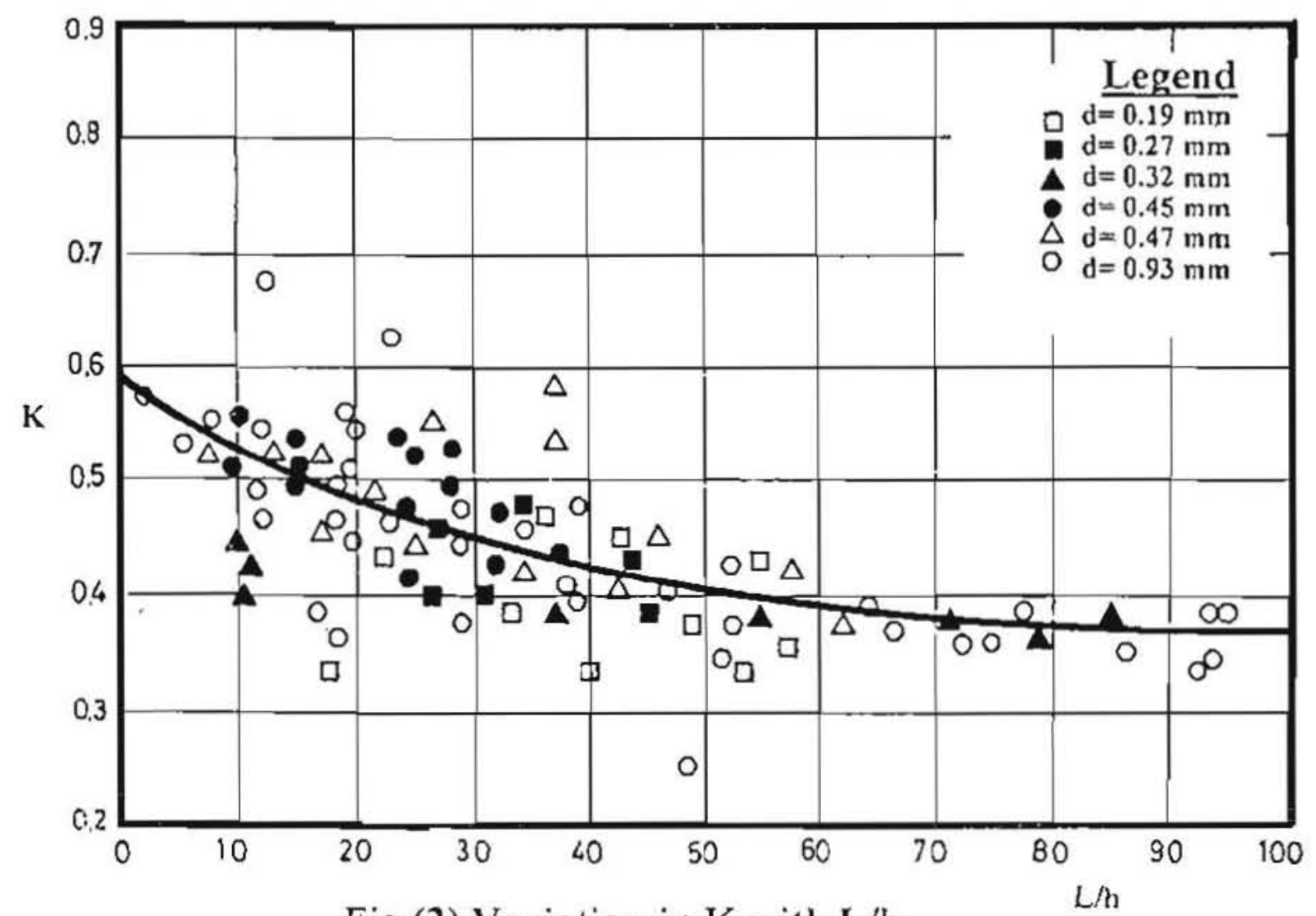

Fig.(2) Variation in $\mathrm{K}$ with $\mathrm{L} / \mathrm{h}$. 
C. 8

M. I. Atlia \& M. M. Elacldin.

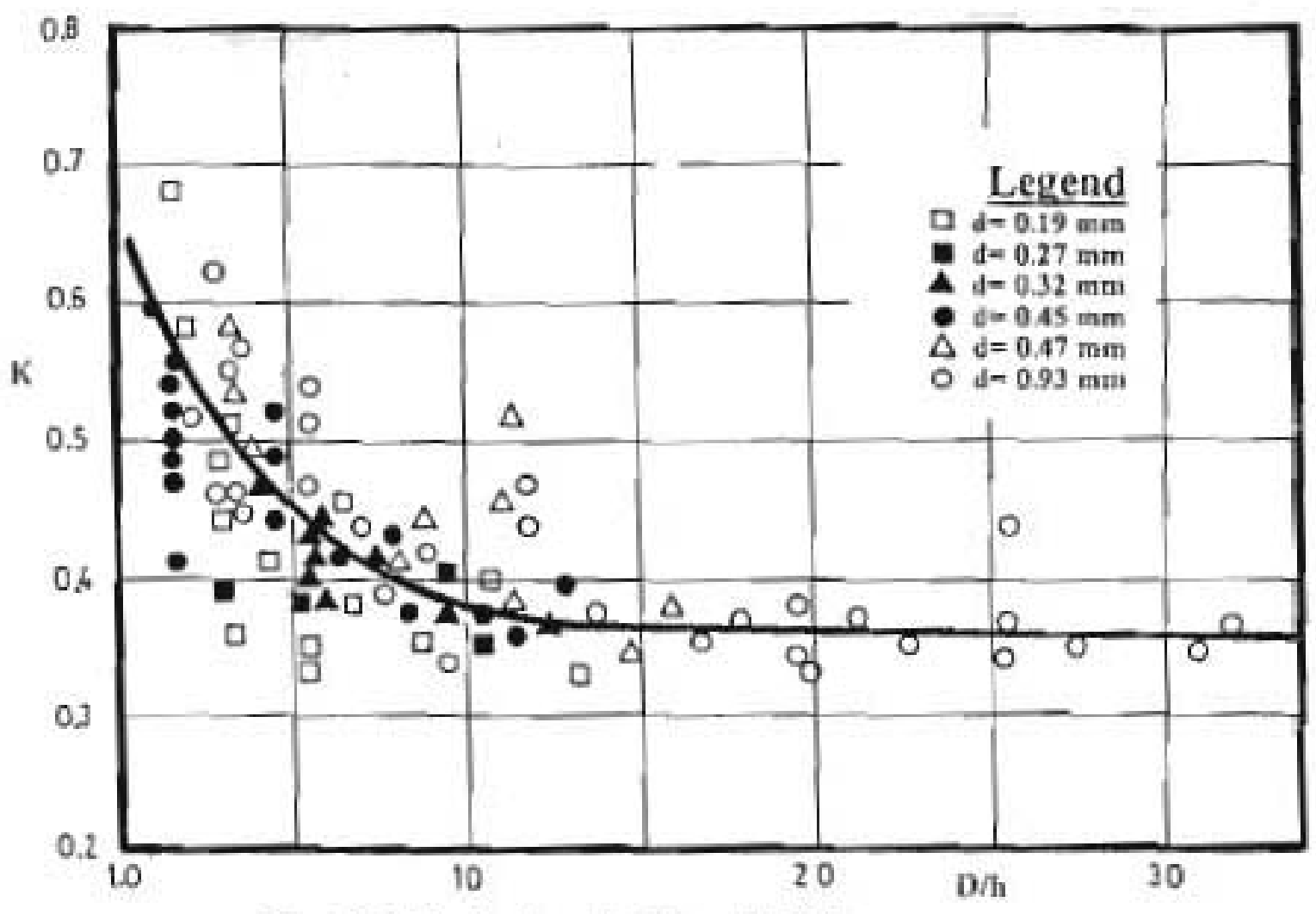

Fig. (3) Variation in $\mathrm{K}$ with $\mathrm{D} / \mathrm{h}$.

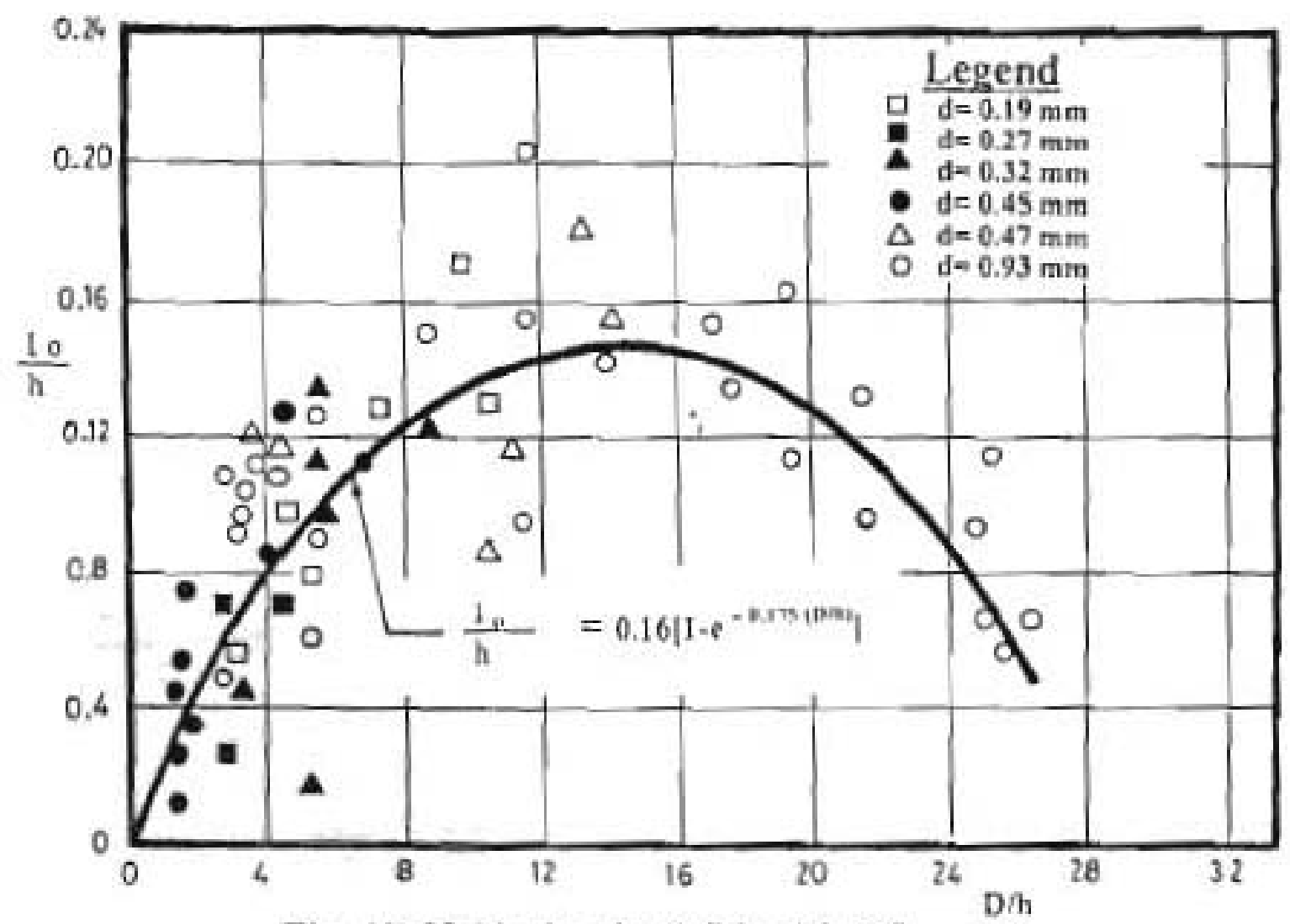

Fig. (4) Variation in $\left(1_{v} / \mathrm{h}\right)$ with $\mathrm{D} / \mathrm{h}$. 
Mansoura Engincering Journal, (MEJ). Vol. 31, No, 4, December 2006.

C. 9

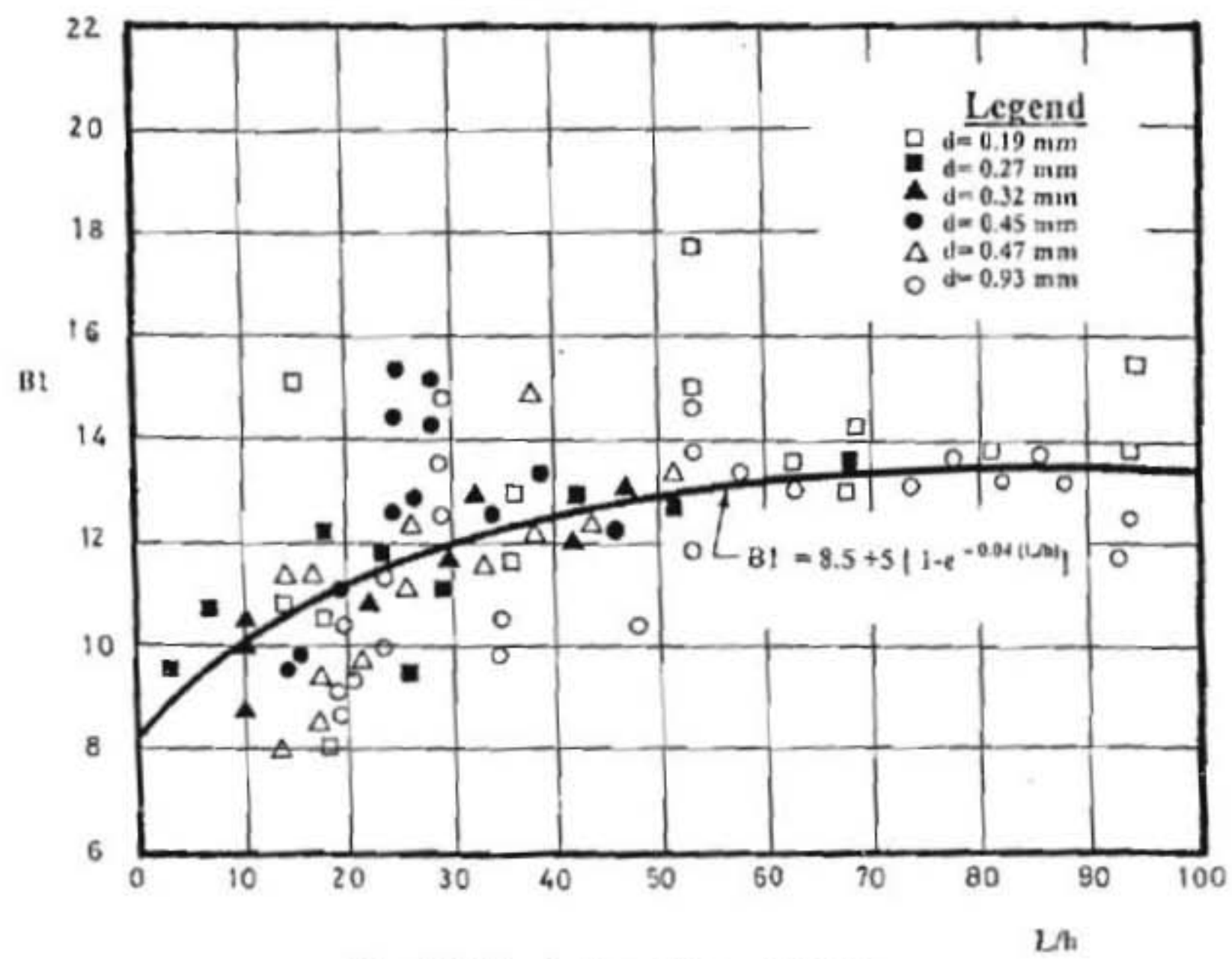

Fig. (5) Variation of $B_{1}$ with $L / h$. 